\title{
BİR MAKALE VE DÜŞÜNDÜRDÜKLERİ
}

\author{
Birten CELIK
}

Çanakkale Muharebeleri, Türk tarihinde önemli bir yere sahiptir. Bu konuda, muharebelerin yaşandığı dönemden günümüze kadạr çeşitli makaleler, kitaplar yazılagelmiştir. Bu çalışmalarin hepsi Çanakkale Muharebelerini farklı boyutlanyla ele alılar. Bunlardan biri de Dokuz Eylül Üniversitesi, Atatürk İlkeleri ve İnkılap Tarihi Enstitüsü'nde 1992'de hazırlanmış ve kabul edilmiş “Canakkale Savașı'nın İzmir Basını'ndaki Yankiları" başlıklı Yüksek Lisans tezimdir ${ }^{1}$. Bu çalışmam, İzmir basınını oluşturan Ahenk, Anadolu ve Köylï gazetelerine dayanarak hazırlanmıştır. Burada üzerinde duracağımız, Prof.Dr.Necmi Ülker'in Atatürk Yolu Dergisi'nde yayınlanan Çanakkale Zaferi'nin İzmir Basını'ndaki Akisle$r i$ " başlıklı makalesidir ${ }^{2}$.

Çanakkale Muharebeleri üzerine yapılan çalışmalar başlık olarak benzerlikler gösterseler de, mutlaka Çanakkale Muharebeleri'nin farklı boyutlarını ele almışlardır. Ancak, Sayın Prof.Ülker'in makalesinde yukarıda konu başlığını verdiğim Yüksek Lisans tezimden kaynak göstermeksizin yapılmıs alıntılar vardır. Prof. Ülker Ege Üniversitesi, Tarih bölümünde görev yapmaktadır. Master tezim de Dokuz Eylül Üniversitesi'nde 1992 yılında hazırlanmıştır. Hocamız 1994'de böyle bir makale hazırlarken, bu tezi görmemiş olması pek mümkün değildir. Kaldı ki tez savunmamda Sayın Prof. UUlker'in görev yaptığı bölümden de öğretim üyesi bulunması, bu iddiamızı güçlendirmektedir. "Çanakkale Muharebeleri ve İzmir Basını" konusu kuşkusuz kimsenin tekelinde değildir. Ancak, bilindiği gibi, bilimsel çalışmalarda yararlanılan kaynakların dipnotlarda verilmesi akademik çalışmaların ilk ve değişmez temel kurallarındandır.

Ben bu çalışmada Sayın PROF. ÜLKER'IN makalesinde tezimden alıntı yapılmış bilgilere işaret edip, onun içine düştüğü bazı yanlışlıkları, çeliçkileri ve eksiklikleri kısaca irdelemeye çalı̧̧acağım. İlginç bir tesadüfle Sayın Prof. Ülker'in makalesinde, benim tezimde yer verdiğim aynı

1 Birten Çelik, "Çanakkale Savașı 'nın İzmir Basını'ndaki Yankıları”, (Basılmamış Yüksek Lisans Tezi, Dokuz Eylül Ûniversitesi, Atatürk Ilkeleri ve Inkılap Tarihi Enstitüsü, 1992) İzmir.

2 Prof.Dr. Necmi Ülker, "Çanakkale Zaferi'nin Izmir Basını'ndaki Akisleri”, Atatürk Yolu, Kasım 1994, Y11. 7, Cilt, 4, Sayı. 14, ss.267-278. 
haber alıntılanın kullanması dikkatimi çekmiştir. Öte yandan, içeriğinde bazı tarih ve bilgi yanlışlıklarına da düß̧müş olması beni bu çalışmaya yönlendirmiştir. Sayın Prof. Ülker'in tezimden alıntı yaptığına inandığım ilk kanıt, kullandığı başlıktır; Canakkale Savaşı'nın İzmir Basını'ndaki Yankıları" ile "Çanakkale Zaferi'nin Izmir Basını'ndaki Akisleri” arasında tek değişiklik Savaş ile Zafer ve Yankı ile Akis sözcüklerindedir.

Öncelikle üzerinde durmak istediğim Sayın Prof. Ülker'in makalesindeki çelişkiler, eksiklikler ve yanlıs saptamalardır. Örneğin Sayın Prof. Ülker, çalışmasında, 18 Mart $1915^{\prime}$ te kazanılan zaferi inceleyeceğini "Yaptığımız bu kısa çalışmanın amacı, Çanakkale'deki bu büyük olayın bir Ege sehri olan Izmir basınında nasıl bir etki ve akis uyandırdığını tespit etmek ve değerlendirmektir." şeklinde açıklıyor ${ }^{3}$. Sayın Ülker burada "İzmir Basını'nda" sözünü kullanmasına karşın sadece Ahenk gazetesinden yararlanmıştır. Oysa, 1915 yılında İzmir'de Ahenkin yanında, nüshalan tam olmasa da Köylï ve Anadolu gazeteleri de vardır. Tek gazete incelenerek bir şehrin basınında, bir olayın yankılarının incelenmesinin eksik bir basınında, bir olayın yankılarının incelenmesinin eksik bir değerlendirme olacağına şüphe yoktur.

Sayın Prof. Ülker'in İzmir gazetelerinin haber kaynaklarını açıklarken de, ilginç bir ifadeyle "Anlasılldı̆ına göre İzmir gazeteleri bu haberleri ya Istanbul'da çıkan C eride-i Havadis ya da Londra, Paris, Berlin ve Italyan v.s gazetelerinden iktibas etmis olduğu bilinmektedir ${ }^{4}$." demektedir. Öncelikle, bu bilgide yer alan "anlasslldı̆̆ına göre" ve “...bilinmektedir” çelişik ifadelerdir. Öte yandan, İzmir gazetelerinin İstanbul basınındaki tek haber kaynağı Ceride-i Havadis değildir, bu okuyucuyu yanlış yönlendirir. Dikkatli incelenirse İzmir gazetelerinin haber kaynağ 1 olarak, İstanbul basınından Tasvir-i efkar ve Tanin gazetelerini de kullandıkları görülür. Yabancı basına gelince, İzmir gazeteleri sadece Londra, Berlin, Paris ve İtalyan gazetelerini değil Bulgar, Romen, Rus, Yunan gazetelerini de kaynak olarak kulllanmaktadır. Bunların yanında, İzmir'de Türkçe yayımlanan gazeteler, o dönemde İzmir'de yayımlanan Rumca Nea Symrne, Amaltiya ve Taros gazetelerini de haber kaynağ olarak alırlar. Izmir gazetelerinin haber kaynakları bu kadarla da kalmaz. Osmanlı Umumi Karargah'ından yayınlanan resmi tebliğler ve bilgiler de önemli kaynaklar oluşturur 5 .

Sayın Prof. Ülker makalesinde, daha önce belirttiğim gibi,büyük bir tesadüf eseri midir? Bilinmez. Ahenk'te yer alan uzun makaleler zinciri arasından tezime aldığım aynı haberleri, bazen kendi cümleleriyle veya

3 Ü̈lker, a.g.m., s.267.

4 Ülker, s.273. (Bundan sonraki dipnotlarda, Ülker olarak verelecektir.)

5 Çelik, ss.12-13. (Bundan sonraki dipnotlarda Çelik olarak verilecektir.) 
aynen alıntılayarak ve bazen de benim yorumlarımı seçerek kullanmıştır. Örneğin, Mart ayı içinde Çanakkale, Cephesi'ndeki İtilaf saldırısıyla ilgili bir haberi; "5 Mart 1331 tarihli Ahenk'te de "Düssman efrenci 4 Mart tarihinde sahilimize çıkarmaya teşebbüs ettiği askerinin duçar olduğu telefatı da kısmen itirafa mecbur kalarak ihraç esnaısnda yalnız yirmi telef, yirmisekiz mecruh vermiy olduğunu yine tebligat-l resmiyesinde zikr ediyor. Halbuki (Kanada) namindaki Fransız hastahane gemisi evvelki gün (Pire)ye muvasalat etmis ve mezkur geminin hariçle ihtilatı men edilmiş olmasına rağmen karaya çıkan mürettabatının ifadesinden gemide üçü̈z mecruh bulunduğu anlaşılmıștır..." alıntılarıyla vermiștim6 . Sayın Prof. Ülker de aynı haberi ancak kendi cümleleriyle; "ayrıca düsman 4 Mart 1915 tarihinde sahillerimize asker çıkarmıs, bu sırada 20 ölü ve 28 yaralı vermis olduğu halde, Pire limanina varan Kanada adli Fransiz hastahane gemisinden yasağa rağmen karaya çıkan gemi mürettabıtından, gemide 300 yaralı olduğu öğrenilmistir." diye vermiş ama kaynak göstermemiştir? . Böylece, bilgiyi tarihsel belge olmaktan çıkarmıştır.

Sayın Prof. Ülker, bazı tarih yanlışlıklarına da düşmektedir. Örneğin, 5 Mart 1915 'te düzenlenen İtilaf saldırısını, çalıșmasında 21 Şubat 1330 tarihli Ahenk gaztesine dayanarak veriyor. 21 Şubat 1330'ın da Miladi takvime göre 5 Mart $1915^{\prime} \mathrm{e}$ denk geldiğini belirtiyor ${ }^{8}$. Bu yanlıştır. Bu tarih, Miladi takvim ve Hicri takvim arasındaki 13 günlük farkla 6 Mart 1915 ' e denk gelir. Ayrıca, o günkü koşullarda bir gazetenin olayları aynı gün iletmesi zaten mümkün de değildir.

İzmir basınında 18 Mart saldırısıysa, resmi tebliğler ve İstanbul bası$\mathrm{n}$ ile yabancı basından yapılan alıntı haberlerle duyurulmuştu. Ancak, bu haberler, 18 Mart'ın ertesi günü "Boğaz'a .bir saldırı daha oldu” şeklinde verilmiş ve iki gün sonrasında resmi tebliğlerle detaylı yer almaya başlamıștı ${ }^{9}$. Sayın Prof. Ülker ise, bu saldırıyla ilgili, 18 Mart öncesi saldırılarla bağlantı kurmaksızın ve yanlış bir haberle şunları yazmıştır; "Bir İzmir gazetesinde 18 Mart 1915 zaferini "Düsman Donanmasının Zayiat-ı Mühimmesi" başlı̆̆ altında ayrıntıl bir biçimde vermektedir ${ }^{10}$." Kaynak olarak da 5 Mart 1331 tarihli Ahenk'i vermiștir. Daha önceki satırlarda değindiğim gibi Hicri Takvim ile Miladi Takvim arasında 13 günlük farkı hesapladığımızda 5 Mart 1331, Miladi takvimde 18 Mart 1915'e denk gelmektedir. 18 Mart 1915'te gerçekleşen bir olayın aynı gün gazetelerde yer alması mümkün değildir. Üstelik "Düssman Donanmasının Zayiat-1 Mühimmesi” başlıklı haber, 18 Mart ile ilgili de değildir. Bu, 18 Mart 1915 öncesi İtilaf saldırılarıyla ilgilidir ve 6 no.lu dipnotla verdiğim haberin

6 Celik, s.75.

7 UUlker, s.270.

8 Ülker, s.268.

9 Celik, s.81-82.

10 Ülker, s.269. 
kaynağıdır. İzmir gazetelerinde 18 Mart ile ilgili ilk resmi tebliğ ve detay içeren makale 7 Mart 1331 (20 Mart 1915) tarihli Ahenk'te verilmiştir ${ }^{11}$.

18 Mart ile ilgili 7 Mart 1331 tarihli Ahenk'te bir de makale yayınlanmıştı. Tezimde bu makaleyi özetleyerek; “...Ingiltere, Fransa ve Rusya'daki siyasi gelişmelerle ilgili yorumlar da önemli haberler arasındaydı. Itilaf devletlerinin bu taarruzlarında siyasi maksatlar bulunduğunu bunların da Yunanistan da dahil olmak üzere diğer Balkan devletlerini de bu taarruzlarla korkutup kendi vanlarında savasa istirak ettirmek..." şeklinde vermiştim ${ }^{12}$. Sayın Prof. Ülker de bu makaleyi, benim alıntıladığım cümlelere de yer vererek; “...Itilaf devletlerinin Canakkale'ye yakın olan Limni, Midilli gibi adalart işgal ettikten sonra Boğaza karşı kuvvet kullanmalarl, Balkan devletlerini. özellikle Yunan kamuovunda etki vapmak hatta korkutmak istedikleri hatıra gelmektedir.." diye yazmışı1 ${ }^{13}$.

Tezimde yer alıpta Sayın Prof. Ülker'in de kullandığı verilerden bir diğeri de, 18 Mart zaferinde büyük payı olan Osmanlı topcularının başarıs1 ile ilgili "Yaşasın Oșmanlılar-Yaşasın Kahraman Topçularımız" başliklı makaledir. Sayın Ülker makalenin başiı̆ını, eksik olarak "Yaşasın Osmanlılar" diye yazmıştır ${ }^{14}$. Tezimde, bu makaleye bir bölümünü alıntılayarak, bir bölümünü de yorumlayarak şöyle yer vermişim; " $B$ u arada Itilaf Donanması'na ăğr kayıplar verdiren Türk Ordusu ve tabii ki topçular hakkında övgü dolu yazılar da İzmir Basını'nı süslüyorduu. Örneğin, "Yaşasın Osmanlılar" - Yaşasın Kahraman Topçularımız" başlıklı bir yazıda düsmanların yirmi parçalık donanmasına karşı "fedakar. cesur topcularımızın sanlı müdaafalarıvla düsmanlarımızın istihkamlarımıza vine fevkalade mühim hasarat ikna edemedikleri" dolaylstyla geri dönmeve mecbur oldukları ve birçok gemilerini de kaybettiklerini böylece artık düşmanların Bogazın geçilemez olduğunu tecrübeleriyle ögrenmiy olmaları gerektiği... ${ }^{15}$ " Sayın Prof. Ülker de makalenin bir bölümünü kendi yorumları ve kullandığım alıntılara da yer vererek; “ Konumuzla ilgili yoğun haberlerin verildiği baş makale ve yorumların yapıldı ̆̆ gazetesinde, 18 Mart zaferiyle ilgili olarak "Yaşasın Osmanlılar" başlıklı uzun bir başmakaleyi kaleme alan Şinasi, Çanakkale Deniz zaferini degerlendirmenin yanında bu olayın siyasi boyutlar hakkında da yorum yapmakta ve doğru teşhisler ortaya koymaktadır. Yazar bu muharebe ile ilgili şu yorumu yapmaktadır ....Fakat avn-i hakla fedakar. cesur topcularımızın sanlı müdafalarıvla düsmanlarımızın istihkamlarımıza yine fevka-

1118 Mart ile ilgili ilk haber 6 Mart 1331 tarihli Ahenk'te yer almıştır. Resmi tebliğlerden ilki 7 Mart 1331, ikincisi 9 Mart 1331, üçüncüsü de 10 Marrt 1331 tarihli Ahenk'te yer almıştır. Çelik, s.81-82.

12 Celik, s.82.

13 UUlker ss.270-271.

14 Ülker, s.271.

15 Çelik, ss.84-85 
lade mühim hasarat ika edemedikleri, yine elim ve yeis ve nevmid ile ricata mecbur olduklarl...." şeklinde vermiştir ${ }^{16} \mathrm{Bu}$ iki alıntı arasındaki farkın takdirini okuyuculara birakıyorum.

Sayın Prof. Ülker tarafından tezimden, üstelik, yanlıs başlıkla kullanılan bir veri de "Şanlı Ordu Var Olsun" başlığıyla 12 Mart 1331 tarihli ahenk gazetesinde yer alan makaledir. Makalenin başlığı, Sayın Ülker tarafından "Şanlı ordumuz" şeklinde değiştirilmiștir. Tezimde bu makaleyi ilgili yorum şöyledir; "Osmanlı Ordusu'nu öven "Sanlı Ordu Var Olsun" başlıklı diğer bir yazıda da ordu ve askerlerin güçlü olduğu ve vatanın herşeyi ile onlara teslim edildiği vurgulanıyor ve düsman devletlerin "Osmanll Ordusu'na catmanin kaca mal olduğunu" Canakkale hezimetinde anladiklarını ve bunu kendilerinin de itiraf etmeye basladıkları belirtiliyordu ${ }^{17} . "$

Sayın Prof. Ülker de bu makaleyi kendi cümleleriyle ve tezimde yaptığım yorumları da kullanarak şöyle vermiştir; "Ahenk gazetesinin "Şanlı Ordumuz" başlıklı başmakalesinde bilinen bir gerçeğe değinilerek, halkımızın mutluluğunu, vatanımızın selametini, Osmanlı devletinin hukuk hakimiyetini gereği gibi temin edecek olanın askerlerimiz olduğu vurgulanmıştır... İtilaf devletleri de Osmanl ordusuna catmanin kaca mal olduğunu ağır kavıplar vererek öğrenmis ve bu hususu da mecburen itiraf etmislerdir.... ${ }^{18,}$

İngiltere'de yayınlanan Daily Chronicle gazetesi'nden 11 Mart 1331 tarihli Ahenk'e yapılan alıntı ve haber tezimde şöyle yer almıştı; "Bu haberlerin yaninda Ingiliz Basinı'n olusturan gazetelerin yorumlart da önemli bir yer tutuyordu. "Daily Chronicle" Gazetesi'nin Canakkale'yi zorlamanin Ingilizlere pek pahalıva mal olacă̌̆ın hatta gazetenin kendi yorumuvla "Fakat biz on onbes torpido ve üc dört zurhll feda ettiğimiz taktirde bile muvafffak olamavacağımıza kat'iyven emin olamavız. Boğazları zorlamak yalnız mühim bir meselevi askerive değ̈l, pek büyük ehemmiveti haiz olan bir meselevi sivasivedir. Canakkale Bogazi Íngiltere için Cebel-i Tarık Boğazı kadar ehemmivetlidir" diyordu ${ }^{19}$ "Sayın Prof. Ülker de aynı gazeteden alıntıyı makalesinde, benim alıntıladığım ayn bölümleriyle; "Ahenk gazetesi, sütunlarında yabancı basından iktibaslar yaparak kamu oyuna dıs kaynaklı bilgileri de sunmuștur. Mart ayında çıkan bir nüshasında ahenk, "Bir Gazetenin Mütalaası" başlı̆̆ altında Ingiltere'de çıkan Daily Chronicle gaztesinin Çanakkale bombardımanının önemi hakkında yazdıklarını aynen asağıdaki sekilde vermistir: "Canakkale'vi zorlamak kevfivetinin bize (Ingilizlere) pek pahalıva

16 Ülker, ss.271-272.

17 Celik, s. 85 .

18 Ûlker s. 275

19 Çelik, s.84 
mal olacağını hesap etmeliviz. Fakat biz 10-15 torpido ve 3-4 zirhlı feda ettiğimiz taktirde bile muvaffak olamavacă̆ımızza kativen emin olmallyız. Boğazları zorlamak yalnız mühim bir mesele-i askerive değil pek büvük ehemmiveti haiz olan bir mesele-i sivasivedir. Canakkale Boğazl ingiltere için Cebelitarı Boğazı kadar ehemmivetlidir ${ }^{20}$."

Sayın Prof. Ülker'in ilginç bir tesadüfle(?!) kullandığı, tezimde de yer alan bir diğer haber de, 18 Mart zaferinden sonra Alman İmparatoru Kayzer Wilhelm II'nin Enver Paşa'ya gönderdiği ve 12 Mart 1331 tarihli Ahenk'te yer alan bir kutlama telgrafiyla ilgilidir. Tezimde; "Almanya Imparatoru Kayzer Wilhelm de Çanakkale Bogazı'ndaki başarıdan dolayı Başkumandan Vekili Enver Paşa'ya telgraf yollayarak tebrik etmistit. Enver Paşa'nın cevabı da söyle verilmisti; “'tebrikatından dolayı teşekküratın ve Osmanl-Alman-Avusturya silahlarinin avn-i hakla sonuna kadar şa'şaa-pas muzafferiyet olacağı itminanını arz eylemişti ${ }^{21}$ " denirken, Sayın Prof. Ülker bunu üstelik gazete tarihini 13 Mart 1331 göstererek şöyle vermektedir; "Yine aynı Izmir gazetesi (Ahenk'i kastediyor) "Telgraf Haberler" kısminda verdiği bir haberde Çanakkale'de kazantlan sanlı galibiyetin müttefikimiz Almanya Imparatoru Wilhelm hazretlerini memnun etmiş ve Başkumandan vekili Enver Paşa'ya bir telgraf çekerek tebrik etmiş, enver Paşa da bilmukabele Kayser'e 'telgraf çekerek teşekkür etmis ve Osmanlı Almanya, Avusturya silahlarınin tanrinin yardımıyla başarılı olacağından emin olması hususunu arz etmiştir ${ }^{22}$ ",

Türk asker ve komutanlarının Çanakkale'de gösterdiği başarılar ve fedakarlıklar, İzmir basınında da 25 Mart 1331 (7 Nisan 1915) tarihli Ahenk'te menkıbelerle yer alıyordu. Tezimde bu menkıbelerden ikisini kullanmıştım. Sayın Prof. Ülker de bu menkıbeleri çalışmasında kullanıyor. "Çanakkale Dilaverlerimizin Menakıb-1 Kahramananesi" başlığıyla yer alan menkıbelerden ikisi tezimde. Tezimde menkıbelerden ikisi şu yorum ve alıntılarla yer alıyor; "25 Mart 1331 tarihli Ahenk gazetesinde 18 Mart 1915 Savaşı'nda Türk askerlerinin gösterdiği bașart ile ilgili yayınladı̆̆ rin) şu tavrı övgü ile anllyordu; "Mustafa oğlu Ibrahim adındaki bir topç çavusunun adeta talimde bulunuyormus gibi, ferah ve pür ve huzur muvezaadan ileri çıkarak, arkadaşlarına yüksek ve ala bir rehberlik ettiği görüldü. Çavuş mütemadiyen yağan düsman mermilerini istihfaf eder bir tavırla, arkadasslarına teveccüh ederek diyordu ki; / Arkadaşlar, anamız bizi bugün için doğurdu. Böylece ve kemal-i cesaret ve şecaatle ateşinize devam etmelisiniz bakın düsmanın hiç bir mermisi bize isabet edemiyor. Halbuki görüyorsunuz ki bizim mermilerimiz, daima düsmanın zırhllları üzerinde patlamakda ve düşmanı mütemadiyen yerini değiştirmeye mec-

20 Ülker, s. 274.

21. Celik, ss.86-87.

22. Ûlker, s.274. 
bur eylemektedir...". Diğer menkıbede de, Yakup oğlu Hüseyin namında ağır obüs topçu neferinin baldırından yaralanmasna rağmen görevinin bassından ayrlmak istemediği ve daha sonra da öldüğ̈̈ belirtiliyordu. Asker ölmeden önce "-Nafile arkadaşlar, hiç usrar etmeyin ben, bir düşman gemisinin battığını görmeyince topumun başından bir dakikacık olsun ayrılmam!.." demişti ${ }^{23}$ ". Sayın Prof. Ülker de, aynı menkıbeleri kullanıyor ve menkıbelerin yer aldığı Ahenk gazetesinin tarihini yanlış olarak, 18 Mart 1331 olarak veriyor ${ }^{24}$.

Sayın Prof. Ülker'in makalesinin "Sonuç" bülümü de, tezimin sonuç bölümünde yer alan yorumlara büyük ölçüde benzemektedir. Üstelik, Sayın Ülker çalışmasında 18 Mart zaferini inceleyeceğini söylüyor, ancak, tezimdeki gibi Çanakkale Muhrebeleri'ni başından sonuna kadar ele almış gibi genel bir yorum yapıyor. Tezimde Sonuç bölümünde, İzmir basınının işlevi ve Çanakkale Muharebeleri üzerine şu yorum ve değerlendirme vardı; “....Bu bağlamda İmir Basını da, onu belirleyen koșullara rağmen Çanakkale Savașı'nı İzmir Kamuoyuna yansıtabileceği en iyi şekilde yansıtmıstır./ ...Osmanlı Imparatorluğu'nun I.Dünya Savașı'na girisinden sonra Çanakkale'ye yönelik saldırilar üzerinde de önemle durmustu. İmir Basını, Çanakkale, Savaşı'nın kaybedilmesinin, Osmanlı Imparatorluğu'nun teslimi anlamına geldiği bilinciyle, Kafkas ve Irak cephelerindede savașların șiddetli geçmesine rağmen bütün dikkatini $\mathrm{Ca}$ nakkale Savaşı üzerinde yoğunlaştırmıştır. Osmanlı Devleti'ni ayakta tutan iç dinamiklerden biri olan Kamuoyunun nabzını her zaman yazdı $\breve{~}$ makalelerle kontrol etmis ve bugünkü savașların cephe gerisini de etkilediğini, yu yüzden hep birlikte elele vererek karşllaşlabilecek her türlü zorluğun üstesinden gelinebileceğini içeren makalelerle İzmir halkının

23 Çelik, ss.85-86.

24 "1-Düsman donanmasından atılan mermiler civarda infilak ettikleri sırada Mustafa oğlu İbrahim adındaki bir top̧̧u çavuşsunun "adeta talimde bulunuyormus gibi" rahat bir şekilde mevziden çıkarak topçu arkadaşlarına rehberlik yaptı̆̆ı görüldü. Dïsman mermilerini hafife alan bir tavir içinde hareket eden çavus arkadaşlarına dönerek "Arkadaşlar anamı bizi bu gün için doğurdu. Böylece ve kemal-i cesaret ve secaatle ateşinize devam etmelisiniz. Bakın düsmantn hiç bir mermisi bize isabet edemiyor. Halbuki görüyorsunuz ki bizim mermilerimiz düsmanın zırhlıları üzerinde patlamakta ve düsman mütemadiyen yerini de ğistirmeğe mecbur etmektedir." sözlerini yüksek sesle söylüyordu. Taarruz eder filonun toplarına karşı cesaretle göğüs geren Mustafa oğlu Ibrahim Cavus'un parlak ve cesaret dolu sözleri topçulartmıza büyük cesaret ve yüksek moral vermiştir.../2- Diğer bir kahramanllk örneğini de Yakup oğlu Hüseyin adındaki bir cesur askerin sözlerinde bulmak mümkündür. Bir ağır obüs topunun numara askeri olan bu kahramanin bir sarapnel parçasıyla baldır etleri kopmus, tezkereci neferler de kendisini batarya haricine çıkarmak istemișlerdi. Cesur topçu eri buna riza göstermiyor, mukaddes bildiği topunun bassından ayrlmak istemiyordu. Vahim bir sekilde yaralanmıs ve kan kaybetmekte olan bu topçu eri, mübarek ruhumu teslim etmek üzere olduğu halde "Nafile arkadaşlar hiç ısrar etmeyin. Ben bir dakikacık olsun ayrilmam" diyerek top başında kalmakta israr ediyordu. Yukarıdaki sözler bu askerin son sözleri olmus ve bir dakika sonra ruhunu teslim etmistir..." Ülker, s.276-277

25 Celik, s.220. 
manevivatanı yüksek tutmava calısmıs ve kanımızca basarmıstı... ${ }^{25}$...Sonç olarak diyebiliriz ki, Çanakkale Savaşı'nın başlangıcında halkı devlete her türlü destek olmaya çağıran İmir Basını, savaş Türkler lehine ilerleyince Türk halkının bu savaşta kazandiğı manevi gücün yavaş yavaş nasıl arttığını çok iyi bir şekilde yansıtmışv ve I.Dünya Savașı'nda Osmanlı Imparatorluğu'nun diğer cephelerdeki savaşma azmine kaynak oluşturmuştur ${ }^{26}$." Sayın Prof. Ülker'in Sonuç kısmında yorumu şöyledir; “...Türk milletinin geleceğini ve onu temsil eden ordusunun yetenek ve şerefini yakından ilgilendiren bu büyük savaş, o dönemin şartları ölçüsünde alınan haberler Izmir basınında geniş ölçüde verilmiş ve büyük yankılar uyandırmıstır. Çanakkale Savaşlarına ilgi gösteren ve manșetlerinde haberler verip yorumlar yapan basın, Izmir sehir ve bölge halkını konuyla ilgili devamlı bilgilendirmis ve bölge halkl moralinin yüksek tutulmasinda önemli bir görevi yerine getirmistir. Hatta, genelde halkın, basarısızlıklarından dolayı ordusuna karşı kaybettiği güvenin tekrar sağlanmasında, Izmir basınının, en azından Ege Bölgesinde olumlu bir kamuoyu oluşmasında ve Osmanlı hükümetine halk desteği să̆lanma konusunda önemli bir rolü ve etkisi olduğunu da söylemek mümkündür ${ }^{27}$.",

Sonuç olarak, Çanakkale Muharebeleri'nin yarattı̆̆ı zaferler, bütün dünya tarafından takdir edilmektedir. Bu konuda ne kadar araştırma yapılsa, ne kadar kitaplar, tezler, makaleler yazılsa azdır. Ancak, bu çalışmalar, bilimsel ahlakın gerektirdiği gibi, daha önce yapılmış olan ve kaynak olarak kullanılan çalışmaları referans göstererek ve bilinenleri tekrar etmeden, yeni bilgiler üretmek için yapılmalıdır. Bilimsel çalışmalar ancak, bu suretle anlamlı ve saygıdeğer olabilirler.

26. Celik, s.223.

27 Ülker, s.278. 